\title{
Rapid indirect enzyme linked immunosorbent assay (ELISA) for detecting antitoxoplasma IgG: comparison with dye test
}

\author{
JANET M FRANCIS, R A PAYNE, D H M JOYNSON The Public Health Laboratory, Singleton \\ Hospital, Swansea
}

SUMMARY A rapid and simple enzyme linked immunosorbent assay (ELISA) for the detection of specific IgG against Toxoplasma gondii was compared with the dye test on 533 serum samples. In general, results were comparable but not with sera that contained high concentrations of toxoplasma specific IgM or that had been heated at $56^{\circ} \mathrm{C}$. There were no false positive results with sera containing rheumatoid factor or anti-nuclear factor.

It is concluded that if a dye test is not to be performed then the serum should be tested for both toxoplasma specific IgG and IgM to avoid misleading results. Heat inactivated serum should also not be tested in this type of specific IgG assay.

Various IgG enzyme linked immunosorbent assay (ELISA) methods for detecting specific antibodies to Toxoplasma gondii have been described, ${ }^{12}$ although the modified dye test remains the definitive test. ${ }^{3}$ In 1983 an IgG ELISA in use at the Toxoplasma Reference Unit of the Swansea Public Health Laboratory was described. ${ }^{4}$ This assay has been simplified and the incubation conditions changed to produce a more rapid test.

We describe an improved ELISA which uses a modified cuticular antigen, and its comparison with the dye test on 533 sera. Sera giving anomalous results were further investigated.

\section{Material and methods}

All wash procedures were carried out with a Titertek microplate washer S8/12. Absorbance readings were made with a Titertek Multiskan MCC (Flow Laboratories, Rickmansworth, Hertfordshire). The coating buffer consisted of $50 \mathrm{mM}$ carbonate/bicarbonate buffer ( $\mathrm{pH} 9.6)$, and the wash solution was $10 \mathrm{mM}$ phosphate buffered saline (PBS) (pH7.3) with $0.05 \%(\mathrm{v} / \mathrm{v})$ Tween 20 added (PBST). The diluent for the serum specimens and conjugate was PBST with $1 \%(w / v)$ gelatin (PBST/G) (EIA purity grade, Biorad Laboratories, Watford, Hertfordshire).

The conjugate was a rabbit anti-human IgG immunoglobulin conjugated to horse radish peroxAccepted for publication 18 February 1988 idase (Dako, Copenhagen). The chromogenic substrate used was $33^{\prime} 55^{\prime}$ tetramethylbenzidene (TMB) (Miles Scientific, Slough) and was prepared and used as described previously. ${ }^{5}$

\section{PREPARATION OF ANTIGEN}

The antigen was prepared from trophozoites of the RH strain of $T$ gondii obtained from the peritoneal exudate of infected mice. ${ }^{6}$ To each $10^{8}$ of washed trophozoites $500 \mu \mathrm{l}$ of distilled water was added. The trophozoites were mixed, frozen at $-70^{\circ} \mathrm{C}$, and then thawed rapidly at $37^{\circ} \mathrm{C}$. The freeze/thaw procedure was repeated three times. After centrifugation at 2000 $\times g$ for 10 minutes the supernatant was discarded, replaced with PBS, and thoroughly mixed. This procedure was repeated three times, resulting in a suspension of toxoplasma "ghosts" devoid of internal components. The suspension was further disrupted in a tissue macerator, the machine being run on maximum power for about 15 minutes. The resulting suspension constituted the antigen and was distributed in suitable aliquots and stored at $-70^{\circ} \mathrm{C}$.

Five hundred and thirty three suitable specimens were selected in sequence for comparison between the dye test and IgG ELISA. Thirty sera known to contain rheumatoid factor and 12 containing anti-nuclear factor were also tested. A further 16 sera collected from patients either early or late in infection were examined. None of these sera was heat inactivated at the Swansea Public Health Laboratory. 
CONTROLS

A local working reference serum (LWRS) was standardised against the World Health Organisation Toxoplasma Reference Serum (WHO International Laboratory for Biological Standards, Copenhagen, Denmark). Both had a dye test titre of 1/2048 and absorbance value of 1.0 in the ELISA system. A panel of six dye test negative sera were used as negative controls (mean absorbance value $<0 \cdot 2$ ).

All tests were set up in flat bottomed Falcon Microtitre polyvinyl chloride flexible assay plates (Becton Dickenson, UK). The optimal dilution of antigen and conjugate was determined by chessboard titrations using the LWRS and the dye test negative control sera. The greatest difference in absorbance values between the positive control and the negative controls was found when the antigen was used at 1/400 and the conjugate at 1/20 000 .

After thorough mixing the antigen was diluted 1/ 400 in coating buffer and distributed in $100 \mu$ l volumes to all wells. After incubation for three hours at $37^{\circ} \mathrm{C}$ the plates were washed three times, dried at $37^{\circ} \mathrm{C}$ for 10 minutes, and stored at $4^{\circ} \mathrm{C}$ in sealed plastic bags.

\section{ELISA METHOD}

Specimens to be tested were diluted 1/100 in PBST/G and $100 \mu \mathrm{l}$ volumes added to appropriate wells of plate coated in antigen. After incubation for 30 minutes at $37^{\circ} \mathrm{C}$ the plate was washed three times and $100 \mu \mathrm{l}$ of conjugate, suitably diluted, was added to each well. After a further incubation for 30 minutes at $37^{\circ} \mathrm{C}$ the plate was washed and $100 \mu \mathrm{l}$ of TMB added to each well and again incubated as before. The reaction was stopped by adding $25 \mu \mathrm{l}$ of $2 \mathrm{M} \mathrm{H}_{2} \mathrm{SO}_{4}$ to each well and mixing. The absorbances were read at $450 \mathrm{nM}$.

To minimise the effect of day to day variation in the absorbance values results were expressed in enzyme immunoassay units (EIUs), as calculated from the following formula:

Test absorbance-mean negative absorbance

$$
\text { EIU }=\text { LWRS-Mean negative absorbance } \times
$$

Experience with this assay has shown that an EIU value of $<10$ can be regarded as negative, 11-20 as doubtful, $21-40$ as low positive, $41-80$ as moderate positive, and over 80 as a strong positive.

\section{Results}

The relative titres of the IgG ELISA compared with the dye test for 533 routine sera are shown in fig 1 . Of 346 sera that were negative by dye test (titre <4), 336 $(97 \%)$ were also negative in the IgG ELISA. Only two (1\%) positive sera, both with a low titre of $1 / 16$, were negative in the ELISA. Ten sera were negative by dye test but gave doubtful or positive results in the IgG

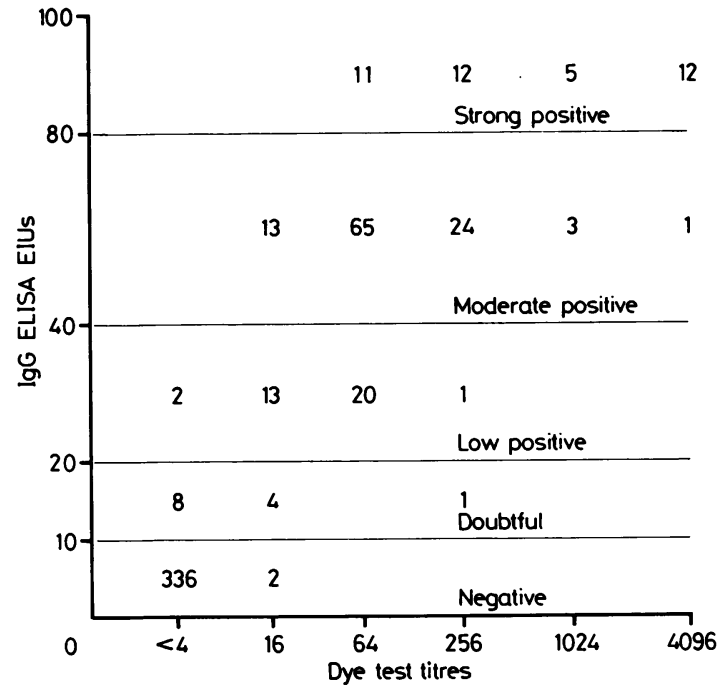

Fig 1 Comparison of IgG ELISA and dye test results obtained with 533 serum samples (a dye test of less than 4 is regarded as negative).

ELISA. Five were from laboratories where sera were heat inactivated at $56^{\circ} \mathrm{C}$ for 30 minutes when examined by a virus complement fixation test before referral for toxoplasma antibody tests. The effect on the IgG ELISA of heat inactivated sera was therefore investigated.

Four aliquots from each of 20 sera shown to be negative by dye test (titre $<4$ ) were prepared. One aliquot of each serum was left unheated, one heated

Table 1 Effect of increasing periods of heat inactivation on dye test negative sera in IgG ELISA (Absorbance values are shown with corresponding EIU values in parentheses)

\begin{tabular}{|c|c|c|c|}
\hline \multirow{2}{*}{$\begin{array}{l}\text { Unheated } \\
\text { absorbance (EIUs) }\end{array}$} & \multicolumn{3}{|c|}{ Heated (hours) } \\
\hline & $0 \cdot 5$ & 1 & 2 \\
\hline $\begin{array}{l}0.058(<1) \\
0.018(<1) \\
0.084(1) \\
0.040(<1) \\
0.020(<1) \\
0.162(8) \\
0.041(<1) \\
0.038(<1) \\
0.059(<1) \\
0.019(<1) \\
0.054(<1) \\
0.029(<1) \\
0.096(2) \\
0.044(<1) \\
0.032(<1) \\
0.045(<1) \\
0.024(<1) \\
0.020(<1) \\
0.020(<1) \\
0.037(<1)\end{array}$ & $\begin{array}{l}0 \cdot 192(11) \\
0 \cdot 189(11) \\
0.285(11) \\
0 \cdot 214(13) \\
0.258(18) \\
0 \cdot 377(29) \\
0 \cdot 373(29) \\
0 \cdot 177(10) \\
0 \cdot 185(10) \\
0 \cdot 117(4) \\
0 \cdot 122(4) \\
0 \cdot 140(6) \\
0.124(4) \\
0.112(3) \\
0 \cdot 126(5) \\
0 \cdot 133(5) \\
0.106(3) \\
0.112(3) \\
0.109(3) \\
0.102(2)\end{array}$ & $\begin{array}{l}0.222(14) \\
0.309(22) \\
0.315(23) \\
0.418(33) \\
0.298(21) \\
0.479(39) \\
0.482(39) \\
0.197(12) \\
0.239(16) \\
0.260(18) \\
0.148(7) \\
0.158(8) \\
0.150(7) \\
0.128(5) \\
0.147(7) \\
0.170(9) \\
0.127(5) \\
0.144(6) \\
0.111(3) \\
0.119(4)\end{array}$ & $\begin{array}{l}0.254(17) \\
0.520(43) \\
0.597(51) \\
0.469(38) \\
0.335(25) \\
0.681(59) \\
0.727(63) \\
0.233(15) \\
0 \cdot 378(29) \\
0 \cdot 295(21) \\
0.205(12) \\
0 \cdot 234(15) \\
0.185(16) \\
0 \cdot 243(16) \\
0 \cdot 246(16) \\
0 \cdot 274(19) \\
0 \cdot 132(5) \\
0 \cdot 144(6) \\
0.135(6) \\
0 \cdot 150(7)\end{array}$ \\
\hline
\end{tabular}


Table 2 Comparison of IgM and IgG results for eight sera taken early and eight taken late in infection

\begin{tabular}{lllll}
\hline \multicolumn{2}{l}{ Early infection } & & \multicolumn{2}{l}{ Late infection } \\
\cline { 1 - 1 } EIU *IgM value & EIU IgG value & & EIA *IgM value & EIA IgG value \\
\hline 161 & 10 & 22 & 43 \\
132 & 17 & 4 & 50 \\
67 & 28 & 8 & 60 \\
93 & 30 & 16 & 80 \\
106 & 30 & 1 & 81 \\
217 & 37 & 18 & 86 \\
90 & 38 & 3 & 89 \\
59 & 42 & 1 & 106 \\
Mean & 29 & 9 & 74 \\
116 & & & \\
\hline
\end{tabular}

*An IgM titre of $<25$ is regarded as negative.

for 30 minutes, one for one hour and one for two hours in a waterbath at $56^{\circ} \mathrm{C}$. The dye tests were negative with all samples after heating for up to two hours but the absorbance values obtained with the IgG ELISA increased significantly (table 1). After heating for 30 minutes the readings for five of the specimens increased into the doubtful range, while two sera became positive. After one hour there were four specimens giving doubtful and six positive results; this increased to eight positive results after two hours of heating. Fig 1 shows that some sera with moderately high dye test titres gave unexpectedly low IgG ELISA results. These specimens proved to be from patients

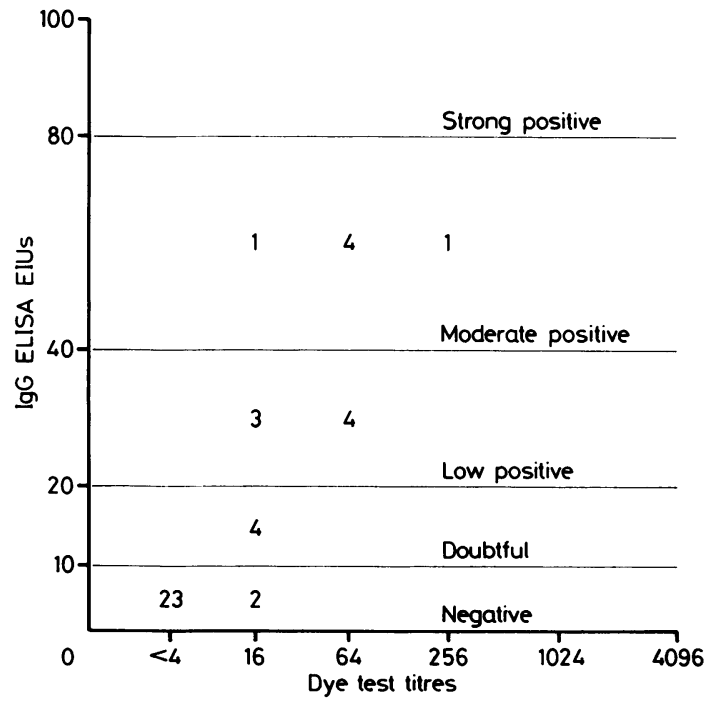

Fig 2 Comparison of IgG ELISA and dye test results for 42 serum samples containing rheumatoid factor $(n=30)$ and anti-nuclear factor $(n=12)$ in addition to various titres of specific antibody. with active toxoplasmic lymphadenopathy and were shown to contain high concentrations of toxoplasma specific IgM antibody when tested in an ELISA system. ${ }^{5}$ To establish if the presence of specific IgM affected the relative values obtained in the IgG ELISA, sera from patients with a recent infection and rising dye test titres (early) were compared with sera from patients known to have been infected at least six months previously and where dye test titres had fallen (late). All sera in both groups had a dye test titre of $1 /$ 128 or $1 / 256$.

The results are summarised in table 2 and suggest that the dye test measures total specific antibody, with the IgM ELISA measuring only specific IgM and the IgG ELISA only specific IgG. When specific IgM is present in the sera the EIUs obtained with the IgG ELISA are relatively low; when specific IgM is no longer detectable the IgG ELISA titres are higher and relate more closely to the dye test titres.

Forty two sera containing rheumatoid factor or anti-nuclear factor as well as various titres of specific antibody against $T$ gondii, were tested in the IgG ELISA and the results compared with the dye test (fig 2). Twenty three sera negative by dye test were all negative with the IgG ELISA. Of the 19 dye test positive sera, 17 gave doubtful or positive results and two were negative.

\section{Discussion}

There are several commercial kits available for detecting toxoplasma specific IgG using an indirect ELISA method. Our experience with the method described showed that anomalous results could occur if the specimens under examination had been heated at $56^{\circ} \mathrm{C}$, particularly if the heating had been prolonged. ${ }^{7}$ The sera giving false positive results in this study were heat inactivated because they were firstly examined in a virus complement fixation test. With the increasing incidence of human immunodeficiency virus (HIV), however, some workers consider that they should heat inactivate sera as a safety precaution. ${ }^{8}$ In view of our findings and the fact that toxoplasmosis is often considered in the differential diagnosis or as a concurrent infection with HIV, we recommend that heat inactivated sera should not be tested in this type of assay for the measurement of IgG class antibodies using a class specific conjugate. At least two of the producers of commercial kits for detecting toxoplasma IgG antibody now state in the instructions that heat inactivated sera should not be tested.

The cause of the increased absorbances obtained with heated sera has not been established but nonspecific, heat-aggregated immunoglobulin may atttach to sites on the solid phase not already occupied by toxoplasma antigen. Attempts were made to over- 
come the problem by quenching the wells with various proteins after the toxoplasma antigen had been attached. Reagents used included lysine, heated rabbit serum, bovine serum albumin, casein hydrolysate and gelatin. While the increase in absorbance values with heated negative dye test sera was reduced using some of these procedures, the problem was not successfully eliminated. (unpublished data).

Of the 533 sera included in the initial comparison, 38 had dye test titres in the range $1 / 128-1 / 256$. Two of these sera with relatively low values in the IgG ELISA were classified as either doubtful or low positive. High titres of toxoplasma specific IgM and the available clinical information indicated that these sera were from patients with a recent infection. By selecting suitable specimens we were able to show that relatively low IgG ELISA values could often be obtained with specimens from patients with recent infection even when the dye test titres were high. Similar results, using IgG and IgM ELISA systems in comparison with the dye test, were found in a study of experimentally induced ovine toxoplasmosis, ${ }^{9}$ and in an evaluation of a commercial kit Balfour et al commented that negative IgG ELISA results could occur with sera containing high titres of toxoplasma specific IgM. ${ }^{10}$

Our findings suggest that the dye test measures total antitoxoplasma antibody and not specific antitoxoplasma IgG alone. It has been shown that IgM fractions of sera from acute cases of toxoplasmosis, obtained by sucrose density gradient centrifugation, give positive dye test results. ${ }^{11}$ Further investigations are being undertaken to determine if the antitoxoplasma specific antibody measured by the dye test includes other immunoglobulin classes besides IgG and IgM. The Sabin Feldman dye test has been proposed as the "gold standard" to which other tests for antitoxoplasma IgG could be compared, ${ }^{12}$ but the above discrepancy must be taken into account in any comparative studies of such tests. The corollary of this is that if a serum is not examined by the dye test then specific IgG and IgM tests must be performed to ensure that patients with early infection are not missed.

Provided the above mentioned disadvantages are recognised, however, this improved IgG ELISA method could be a very useful test in the serological diagnosis of toxoplasmosis. The assay is simple and rapid to perform, requiring only one and a half hours' incubation time; the previously described method required overnight incubation. ${ }^{4}$ The modified cuticular antigen used in this study may be the responsible factor for the shorter incubation times.

Sera containing rheumatoid factor or anti-nuclear factor have often been reported as the cause of false positive results in antibody capture assays for specific IgM but not in the type of indirect assay described here. One commercial producer of an indirect assay for toxoplasma IgG (Labsystems Oy, Helsinki 81, Finland), states in the instructions that samples containing high values of rheumatoid factor may occasionally give falsely raised results. The sera containing rheumatoid factor or anti-nuclear factor tested in the described assay did not give falsely raised results.

Expressing results as EIUs permits direct comparison of assay runs, irrespective of absolute absorbance values, and has proved valuable for attempting comparisons of different assay formats. Problems of too much or too little substrate colour development are also largely eliminated, with full controls on each microtitre plate.

\section{References}

1 Voller A, Bidwell DE, Bartlett A, Fleck DG, Perkins M, Oladehin B. A microplate enzyme-immunoassay for toxoplasma antibody.J Clin Pathol 1976;29:150-3.

2 Walls KW, Bullock SL, English DK. Use of the enzyme-linked immunosorbent assay (ELISA) and its microadaption for the serodiagnosis of toxoplasmosis. J Clin Microbiol 1977;5:273-7.

3 Fleck DG, Kwantes WW. The laboratory diagnosis of toxoplasmosis. Public Health Laboratory Service, Monograph series 13. London: HMSO, 1980.

4 Francis JM. Enzyme-linked immunosorbent assay for the detection of toxoplasma IgG antibody: a comparison with other serological tests. Med Lab Sci 1983;40:327-31.

5 Payne RA, Joynson DHM, Balfour AH. Public Health Laboratory Service enzyme-linked immunosorbent assay for detecting toxoplasma specific IgM antibody. J Clin Pathol 1987;40:276-81.

6 Francis JM. A contribution towards the antigenic analysis of Toxoplasma gondii. Med Lab Sci 1983;40:319-25.

7 Francis JM, Payne RA, Joynson DHM. False positive results with heated sera in Toxoplasma ELISA for IgG antibody. $J$ Clin Pathol 1987;40:36.

8 Spire B, Dormont D, Barre-Sinoussi, et al. Inactivation of lymphadenopathy-associated virus by heat, gamma rays and ultraviolet light. Lancet 1985; i:188-9.

9 Payne RA, Joynson DHM, Wilsmore AJ. Enzyme-linked immunosorbent assays for measurement of specific antibodies in experimentally induced ovine toxoplasmosis. $J$ Epidemiol Infect 1988;100:205-12.

10 Balfour AH, Harford JP. Detection of specific IgG and IgM antibodies to Toxoplasma gondii with a commercially available enzyme immunoassay kit system. J Clin Pathol 1985;38:679-89.

11 Payne RA, Isaac M, Francis JM. Enzyme-linked immunosorbent assay (ELISA) using antibody class capture for the detection of antitoxoplasma IgM. J Clin Pathol 1982;35:892-6.

12 Brooks RG, McCabe RE, Remington JS. Role of serology in the diagnosis of toxoplasmic lymphadenopathy. Rev Infect Dis 1987;9:775-82.

Requests for reprints to: Dr D H M Joynson, Consultant Medical Microbiologist, Public Health Laboratory, Singleton Hospital, Sgeti, Abertawe, Swansea SA2 8QA, Wales. 